\title{
Discussion on Some Problems in the Development and Design of Medium and Small-Sized Housing
}

\author{
Jin Fan \\ Henan Institute of Engineering \\ Institute of Art Design \\ Zhengzhou, China \\ fan850228@163.com
}

\begin{abstract}
A huge contracdition between housing construction and china's state situations, people's housing needs has arisen. Some problems existing in the housing develop in china are analyzed, and it is verified that medium and small-sized housing will be a mainstream of housing develop. Discussion on the difficulties of medium and small-sized housing construction, existential problems and some mistake in medium and small-sized housing design was achieved. The discussion results have an important practical guidance significance for the development and design of medium and small-sized housing in the immediate future.
\end{abstract}

Keywords-medium and small-sized housing; residential development; residential design; people-oriented.

\section{PROBLEMS EXISTING IN THE HOUSING DEVELOP IN} CHINA

A huge contradition between the housing construction and basic state situations, people's housing needs has arisen, many problems and contradictions are always discovered and it urges the housing problems of mediun or low-income stratum. Some main problems existing in the housing development are as followed.

\section{A. Outstanding Contradiction between Housing Supply and Demand}

With the acceleration of urbanization and an influx of immigrants into cities, the size of urban residential land is becoming increasingly large. Experts say that the urbanization level of our country will exceed 50\% by 2020 . With the acceleration of urbanization process, it urges the adaptation to real estate industry. According to the urban population by 2010, with an additional increasing $1 \mathrm{~m}^{2}$ per residential area, it may built about 666 million $\mathrm{m}^{2}$ residential area. According to eight hundred million urban population predicted by 2020 , and according to $22 \mathrm{~m}^{2}$ per residential area is calculated, then additional residential area of 2.95 billion $\mathrm{m}^{2}$ will be built, which is used to meet the new population increase of 134 million population. At present, the amount of residential construction can not far satisfy the requirements each year.

\section{B. The Imbalance in Housing Suply Structure}

In recent years, high-priced and large units housing has a high proportion, but the commodity housing with small and medium sized, medium and low-cost are in short supply, which cannot satisfy the requirements for medium and lowincome families. So we must take practical measures to solve the housing needs for medium and low-income families, which also are some necessary measures for the implement the "people-oriented" policy and the establishment a harmonious society[1]. From the economic capacity and consumption levels of ordinary people point of view, they cannot far afford a large area residence. Due to large area and high price for commodity housing, a few househoids can afford to buy it, and appear the situation with oversupply in the market, and vacancy rates of commodity housing have remained stubbornly high. On the other hand, the majority of the working class is looking at the housing helplessly.

\section{The great waste of resources caused by residential construction}

Our country has large population, the resources are relatively insufficiency. A large amount of resources are occupied and output by housing construction. It is important for the rational and efficient use of land resources, and providing a suitable housing for a large amount of urban population, especially for the limited economic capacity crowd.

\section{The lack of human nature concern in the housing design}

The housing is the physical support of the family and the life, it is just as the basis for human survival as clothes and food.The housing is designed for the people and served for the people, so it should safty the basic needs for the people everywhere. but a lot of designers and developers often ignore this. The following respects are as shown:

a) Housing area is too large, and the unbalance in its size, and copied in its flat, and the lack of creativity.

b) The housing is grandiose, a vertical modeling of it is chaotic, the lack of new ideas in the environmental design, not pay attention to the harmony with the surrounding environment, undermining the overall landscape of the city. 
c) Housing design is a characterisic of extraordinary luxury,but not enough care for the housing meeds for the people

d) Culture has become a propaganda in the first place, it become a business profitable tool.

e) They live in an increasingly indifferent neighborhood with one another.

f) The developer action is done for financial gain, while they ignors the project quality.

The above problems in housing development process would first accumulate, then it will seriously affect the healthy development of housing in our country. It is imperative to adjust the housing suply structure of China, and to is done for people's demands. From the urbanization, the changes in family structure and consumption structure and other point of view, medium and small-sized apartment will be a mainstream and a rational regression of housing development.

\section{THE DIFFICULTIES OF MEDIUM AND SMALL-SIZED HOUSING CONSTRUCTION}

Real estate developers are always paid little attention to the medium and small-sized housing, four main reasons are as followed.

\section{A. For the Medium and Small-sized Housing, it has a Large Amount of the Wall and Water pipelines}

under a background of regarding the quality and value as the competition core, its construction costs are incresed and its price competitiveness is reduced[2].

\section{B. The Room Rate of Medium and Small-sized Housing is Low.}

Its building area is small, but the number of its internal function space is not significantly reduced, and the rate of the wall has increased. The room rate is much lower than the large house except for an open design.

\section{The Money Collecting Velocity of Medium and Small- sized Housing is Slow and High Risk Investments for Medium and Small-sized Housing.}

The money collecting velocity of it is much lower than large house for the same propaganda.

\section{It Is Very Difficult to Push up House Prices of Medium and Small-sized Housing.}

The purchaser of medium and small-sized housing is most of working-class, so they is relatively higher sensitivity to the housing price. After the development rate of medium and small-sized housing is occupied the upper hand, the development cost shall be raised, and house prices will be also raised.

Whatever there are some types of construction difficulties, generally speaking, total price of medium and small-sized housing is always lower than the big house. In recent years, the growth rate of house price is much greater than the income growth, so it is an inevitable trend for the great mass of working-class to pay attention to the medium and small-sized housing. The "90 • 70" policy has only made this concern become more urgent and strengthen the inevitability[3].

\section{EXISTENTIAL PROBLEMS IN MEDIUM AND SMALL- SIZED HOUSING DESIGN}

\section{A. Existential Problems in Medium and Small-sized Housing Design}

With the rapid development of the economy, housing ideas and needs of urban residents have changed from the survival type to the comfortable type, and the economy, the applicability and the comfort has become a major trend in the present residential development. Due to the limitations of their own conditions and the differences in their understanding, there are some problems at this stage in medium and small-sized housing design:

1) A lack of recognition on medium and small-sized housing

Affected by the comparison psychology, they always think that "living off" get bigger and better for the housing area, which would lead to the blind expansion of housing areas and the lack of the study on medium and small-sized housing. Medium and small-sized housing is transitional architecture for small area, and it is a synonym for low standard and shabby house, it is boycotted by the consumers, developers and designers. Moreover, the development of medium and small-sized housing is in conflict with the original standards and specifications. For example, the minimum areas of the bedroom and living room is defined in order to improve the comfort of the rooms in the original standards, which would violate the regulation in medium and small-sized housing design. Many designers think that medium and small-sized housing limits their creations, even if good design work is also not recognized by the market, so there is an inimical mentality for medium and small-sized housing, which would hinder the development of medium and small-sized housing design.

2) Poor livability and comfort

Now, for the medium and small-sized housing, some are modified by poor sales large housing, some are built hurriedly to cater to the market needs, some are taken the role of seam filling in large-sizes housing. Which would result in some deficiencies for medium and small-sized housing in the market[5].

a) In space design, the apartment is simple with a limited area.

b) Each functional space interaction, such as the interaction between the living room, an audio room, reading and other space bring inconvenience in practical use. 
c) The kitchen and toilets space design has their deficiencies; some details cannot be attached any importance, such as there is no a reasonable position for washing machine, and no a balcony for hanging clothes.

d) Because the building must maintain a certain depth, it is not easy to hold overall consideration, most of house do not permit good light and air to enter. Medium and smallsized housing has a north-facing aspect in most mixed building, which has a detrimental effect on a healthy living, so it has poor livability and comfort.

3) Low flexibility and variability

As a physical entity of residence, physical aging time of the structure is about 100 years, functional aging time of the residence is only about 20 years. With the variety and changeability of our lifestyles, there is an increasing asynchrony between physical aging time of the structure and functional aging time of the residence. In order to take advantage of physical life cycle of the building to adapt the evolution of family life and life cycle, it is necessary for the residence to design with flexibility and variability. Especially for medium and small-sized housing, it is very important for the design with flexibility and variability.

At present, medium and small-sized housing has a lack of good flexibility and variability, and it can not agree with the different needs of different tenants dwelling layout, so it can not satisfy long-term need of the people. How to design medium and small-sized housing with flexibility and variability, and how to make it "grow" and gain a sustainable development, which is a major problem to be addressed in the medium and small-sized housing design.

\section{B. Some Mistake in Medium and Small-sized Housing Design}

After the promulgation of New Policy "National SixPoints", some developers and designers begin without their "people-oriented" points to consider the fine design, but to circumvent national policy and make the design of medium and small-sized housing fell into erroneous zone: Such as in the design, They reserve a nonbearing wall between households and households to easily get through, two apartments when they buy, but a large house when the wall is demolished. Or in the design, They reserve a passageway between upper and lower layers of the buliding, when the owners demolish a floor and add the stair, the building becomes a large apartment. The above ways would destroy the architectural structures, no a reasonable design way for medium and small-sized housing. If these problems can not be solved duly, not only hinder the healthy development of medium and small-sized housing, but also can not make people's living level enhanced substantially. From China's actual conditions, medium and small-sized housing may continue to exist and develop in a long period of time, and it will play a more important role in the future of city house. Medium and small-sized housing may occupy a mainstream position in the real estate market, and the arrival of the house purchasing period is represented. How to improve the comfort of medium and small-sized housing? How to do the "A sparrow may be small but it has all the vital organs"? How to achieve product innovation under the premise of complying with the new regulations? These are the main problems we are to be resolved.

\section{REFERENCES}

[1] X. P. Dong, "Study on the Current Housing Design of Medium and Small-sized Type in China," Xi'an: Xi'an Univerity of Architecture and Technology, 2008.

[2] Q. Ji, "Study on the Housing Design and Development of Medium and Small-sized Type in China," Zhengzhou: Zhengzhou University, 2007.

[3] R. G. Wang, "Some Thinking and Actions on Medium and Smallsized Housing," Urban Development, vol.10, 2006, pp. 44-45.

[4] J. Yan and H. Chang, "Problems and Design Principles Exsiting in Medium and Small-sized Housing Design,” Science and Technology Innovation Herald, vol. 11, 2011, pp. 43.

[5] J. Q. Guo, "Several Common Problems in Medium and Small-sized Housing Design,” Science \&Technology Information, vol. 29, 2010, pp. 62. 